\title{
USO DO ÍNDICE DE DEGRADAÇÃO DE AMIDO NA DETERMINAÇÃO DA MATURIDADE DA MANGA 'TOMMY ATKINS' '
}

\author{
RAILENE HÉRICA CARLOS ROCHA ${ }^{2}$, JOSIVAN BARBOSA MENEZES ${ }^{3}$, EUCLIDES ALVES DE MORAIS ${ }^{4}$, \\ GEOMAR GALDINO DA SILVA ${ }^{5}$, MÁRCIA MICHELLE DE QUEIRÓZ AMBRÓSIO ${ }^{6}$ E \\ MARIA ZILDERLÂNIA ALVEZ ${ }^{6}$.
}

\begin{abstract}
RESUMO - Instalou-se um experimento com manga 'Tommy Atkins' objetivando estudar a eficiência do índice de degradação de amido visando a sua utilização em nível de campo como mais uma alternativa para estimar a maturação dos frutos. A eficácia do método foi estabelecida pela sua correlação durante a maturação com o conteúdo de amido e com a coloração da casca, coloração da polpa, firmeza da polpa, $\mathrm{pH}$, acidez total titulável, sólidos solúveis totais e açúcares redutores e não redutores. O ensaio foi instalado em delineamento inteiramente casualizado, composto por cinco tratamentos, com base na coloração da polpa e da casca. No caso da polpa: I - fruto verde; II - verde com traços de amarelo; III - mais verde que amarelo; IV - mais amarelo que verde; e V - traços de verde. Para a coloração da casca, adotou-se a mesma escala com variação de verde para vermelho. Utilizaram-se seis repetições por tratamento. Em geral, houve boa correlação entre o índice de degradação do amido e as outras variáveis estudadas, sendo que o índice de coloração da polpa apresentou melhor coeficiente de correlação. As análises de correlação indicam que o método pode ser utilizado pelo produtor.
\end{abstract}

Termos para indexação: Mangifera indica L., índice de colheita, maturidade.

\section{USE OF THE STARCH DEGRADATION INDEX FOR DETERMINING MATURITY IN MANGO 'TOMMY ATKINS'}

\begin{abstract}
An experiment was carried out to study the efficiency of the starch degradation index for estimating maturity in mango 'Tommy Atkins' aiming its utilization as an alternative method at field. The efficiency of the method was evaluated through correlations between the index and each of the following traits: starch content, skin color, pulp color, pulp firmness, $\mathrm{pH}$, titratable acidity, soluble solids, reducing sugars, and non-reducing sugars. The experiment was completely randomized with five treatments and six replications, and was based on pulp and skin colors. The treatments regarding pulp color were: I - green; II - green with yellow traces; III - greener than yellow; IV - yellower than green; and V - with traces of green. With respect to skin color, it was utilized the same scale with the color varying from green to red. Generally there was good correlation between the index and each one of the traits studied, however pulp color had the best correlation coefficient. The correlation analyses indicate that the grower can utilize the method.
\end{abstract}

Index terms: Mangifera indica L., harvest index, maturity.

\section{INTRODUÇÃO}

Perdas em quantidade e qualidade ocorrem nos produtos agrícolas desde a colheita até o consumo, especialmente pela alta perecibilidade. Para determinar o grau de maturação, utilizam-se vários métodos, nos quais, devem-se levar em conta as características próprias de cada variedade de manga. Não existe um sistema que possa ser aplicado sem algum ajuste a todas as variedades desta fruta (PROTRADE, 1992; Sañudo et al., 1997).

Quando os frutos são colhidos muito desenvolvidos ou completamente maduros (com casca pouco resistente e polpa mole), são muito sensíveis às batidas e aos ataques de doenças, fatores que reduzem o tempo de armazenamento, com os frutos apresentando problemas durante o manuseio, armazenamento e transporte, se são colhidos imaturos e imediatamente armazenados, apresentam baixa qualidade, além de serem muito suscetíveis à perda de água e a desordens fisiológicas, sendo essencial a colheita dos mesmos no correto estádio de amadurecimento para facilitar o transporte a distância, amadurecimento normal e aumentar o período de armazenamento.

A determinação do ponto de colheita através do índice de degradação de amido e do conteúdo de amido vem sendo estudada em maçãs pelos autores Brookfield et al. (1997) e Fan et al. (1995). O teste de amido pela solução aquosa de iodoiodeto de potássio detecta a presença de amido em produtos vegetais através do desenvolvimento de uma coloração escura.

O objetivo deste trabalho foi estudar a eficiência do índice de degradação de amido em manga 'Tommy Atkins',

\footnotetext{
1 Trabalho ${ }^{\circ}$ 177/2000. Recebido: 14/08/2000. Aceito para publicação: 18/07/2001.

2 Eng. Agr ${ }^{\circ}$ - bolsista CNPq, mestranda do curso de Fitotecnia da ESAM, c. p. 137, CEP 59.625-900, Mossoró-RN.

3 Eng. Agr $^{\circ}$ - Dr. em Ciência dos Alimentos, ESAM - QTC, c. p. 137, CEP 59.625-900, Mossoró-RN.

4 Eng. Agr $^{\circ}$ - M.Sc em Bioquímica - ESAM - QTC, c. p. 137, CEP 59.625-900, Mossoró-RN.

5 Eng. Agr - M.Sc em Fitotecnia - ESAM - QTC, c. p. 137, CEP 59.625-900, Mossoró-RN.

6 Eng. Agr $^{\circ}$ - ESAM, c. p. 137, CEP 59.625-900, Mossoró-RN.
} 
visando a sua utilização em nível de campo como mais uma alternativa para estimar a maturação dos frutos através da correlação deste índice com as mudanças no conteúdo de amido, coloração da casca, coloração da polpa, firmeza da polpa, $\mathrm{pH}$, acidez total titulável, sólidos solúveis totais e açúcares redutores e não redutores.

\section{MATERIAL E MÉTODOS}

Os frutos da manga 'Tommy Atkins' foram obtidos de um pomar comercial instalado no município de Carnaubais - RN. A colheita foi feita em cinco estádios de maturação, baseandose na cor da casca e da polpa. No caso da polpa, seguiu-se a escala: I - fruto verde; II - verde com traços de amarelo; III mais verde que amarelo; IV - mais amarelo que verde; e V traços de verde, conforme PROTRADE (1992). Para a coloração da casca, utilizou-se a mesma escala, variando da coloração verde a vermelho.

As análises visuais, físicas e químicas foram iniciadas seis horas após a colheita dos frutos. $\mathrm{O}$ experimento foi instalado no Laboratório de Pós-Colheita da ESAM, adotando-se o delineamento inteiramente casualizado, composto por cinco tratamentos (estádios de maturação) e seis repetições, sendo dois frutos por repetição.

A medida da firmeza foi feita em regiões equatoriais da superfície do fruto desprovido de casca, utilizando-se de um penetrômetro Mc Cormick modelo FT 327, com ponteira de 7, 8 mm de diâmetro e os resultados expressos em Newton (N). Em seguida, os frutos foram cortados longitudinalmente em duas partes. Uma parte foi utilizada para o pincelamento da polpa com solução aquosa de iodo-iodeto de potássio preparada na proporção de 2,0 mg $\mathrm{I}_{2}$ : 20,0 mg KI : 1,0 mL $\mathrm{H}_{2} \mathrm{O}$, descrita por Fan et al. (1995) e a outra parte foi reservada para as análises químicas. $\mathrm{O}$ índice de degradação de amido foi determinado utilizando uma escala subjetiva, modificada de Brookfield et al. (1997), onde: 0 = tecido escuro, totalmente tingido; $1=$ clareamento inferior a $10 \%$ no centro da polpa; 2 = clareamento no centro da polpa entre $10 \%$ e $20 \% ; 3$ = clareamento entre $20 \%$ e $30 \%$; $4=$ clareamento entre $30 \%$ e $40 \% ; 5=$ clareamento entre $40 \%$ e $50 \%$; e $6=$ clareamento superior a $50 \%$. As notas foram atribuídas após cinco minutos da aplicação da solução aquosa de iodo-iodeto de potássio.

A parte do fruto reservada para as análises químicas foi processada de duas formas; a partir da primeira, obteve-se o suco para as análises de $\mathrm{pH}$, acidez total titulável, sólidos solúveis e açúcares redutores e não redutores. $\mathrm{O}$ suco foi extraído em uma centrífuga doméstica. A outra porção da polpa foi homogeneizada em liquidificador, congelada e liofilizada durante 48 h, para a determinação do teor de amido.

A acidez potenciométrica $(\mathrm{pH})$ foi determinada em potenciômetro digital e a acidez total titulável, por titulação, expressa em mmol H $\mathrm{H}^{+} / \mathrm{L}$. O conteúdo de sólidos solúveis totais (SST) foi determinado em refratômetro digital, conforme normas da AOAC (1992) e expressos em porcentagem.

O conteúdo de amido foi determinado através de espectrofotometria de acordo com a metodologia proposta por Silva (1981). Os resultados foram expressos em porcentagem de matéria fresca.
Os açúcares redutores e não redutores foram analisados pelo método de Somoghy-Nelson (Southgate, 1991). Os resultados foram expressos em gramas de glicose por $100 \mathrm{~mL}$ de suco.

As análises de variância e de correlação dos dados foram efetuadas utilizando-se do software SPSSPC (Norusis, 1990).

\section{RESULTADOS E DISCUSSÃO}

Entre as variáveis estudadas (Tabela 1), a coloração da polpa apresentou melhor coeficiente de correlação. O amadurecimento dos frutos de manga foi caracterizado por mudanças na coloração dos tecidos da casca e da polpa, passando de verde-oliva, no primeiro estádio de maturação, para vermelho no último estádio, no caso da casca; e de branca, no estádio I, para laranja, no estádio $\mathrm{V}$, no caso da polpa. Os menores e maiores índices de degradação de amido foram encontrados, respectivamente, nos estádios $\mathrm{I}$ e V; estes foram também para a coloração da casca e da polpa (Tabela 2).

A forte correlação entre o índice de degradação de amido e a coloração da casca e da polpa (Tabela 1) indicou que, quanto mais verde a casca e quanto mais branca a polpa, maior a área do fruto tingida pela solução de iodo. Nos estádios mais avançados, quanto mais vermelha a casca e mais laranja a polpa, menor a área do fruto tingida pela solução. Conforme Bleinroth (1994), a fruta estará no ponto de ser colhida quando um terço da área compreendida entre o caroço e a casca, e em torno deste, permanecer esbranquiçado, indicando que não mais existe amido nessa região.

A firmeza da polpa diminuiu com o avanço da maturação (Tabela 2), variando de $96,14 \mathrm{~N}$ a 9,40 N, nos estádios II e V, respectivamente, similar ao verificado por Mizrach et al. (1997) em manga 'Tommy Atkins' e por Ketsa et al. (1999) em manga 'Nam Dokmai'.

A firmeza da polpa, acidez total titulável e o conteúdo de amido tiveram correlação negativa com o índice de degradação de amido; os demais índices utilizados para determinar o ponto de colheita em manga apresentaram correlação positiva com o índice de degradação de amido; exceto os açúcares redutores que não se correlacionaram significativamente (Tabela 1).

Ocorreu diminuição na acidez total titulável e aumento no $\mathrm{pH}$ com o avanço da maturação (Tabela 2). O estádio de maturação I apresentou menor valor de $\mathrm{pH}$, concordante com a concentração mais elevada de acidez total titulável. Este comportamento decorre do consumo de ácidos orgânicos no processo respiratório.

O maior conteúdo de amido foi $6,81 \%$, registrado no estádio de maturação I, e o menor foi 3,04\%, verificado no estádio V (Tabela 3). Decréscimo de amido durante a maturação também foi observado por Maia et al. (1986) nas cultivares de manga Coité, Jasmim, Itamaracá, Rosa e Espada, registrando variação de 9,36\% (Espada, 'de vez' ) a 0,65\% (Itamaracá, madura). Nos frutos, o amido acumulado degrada-se e converte-se em açúcares solúveis, também diminui a acidez e ocorre a degradação paulatina das paredes celulares, que torna a firmeza da polpa mais suave (Sañudo et al. , 1997).

$\mathrm{Na}$ cultivar Harumanis, o decréscimo em ácidos orgânicos durante o amadurecimento foi acompanhado por um 
decréscimo em amido e concomitante aumento em sólidos solúveis e sacarose; o decréscimo em ácidos orgânicos foi verificado com maior rapidez no interior do mesocarpo do que na periferia do mesmo, sugerindo que, no interior do tecido, o metabolismo e a respiração são mais ativos durante a maturação (Lazan, 1993).

O aumento nos conteúdos de açúcares totais, açúcares não redutores e sólidos solúveis totais durante a maturação está de acordo com a redução concomitante do conteúdo de amido nos frutos ao longo da maturação (Tabela 3), demonstrando crescente conversão de amido em açúcares simples. No estádio

Tabela 1 - Coeficientes de correlação (r) para as variáveis cores da casca, cor da polpa, sólidos solúveis totais, amido, firmeza da polpa, pH, acidez total titulável, açúcares totais, açúcares redutores, açúcares não redutores, correlacionadas com o índice de degradação de amido em manga 'Tommy Atkins'. ESAM, Mossoró-RN. 2000.

\begin{tabular}{lc}
\hline \multicolumn{1}{c}{ Variáveis } & Índice de degradação de amido \\
\hline Cor da casca & $0,9233^{* *}$ \\
Cor da polpa & $0,9514^{* *}$ \\
Sólidos solúveis totais & $0,8781^{* *}$ \\
Amido & $-0,7423^{* *}$ \\
Firmeza da polpa & $-0,8694^{* *}$ \\
PH & $0,8528^{* *}$ \\
Acidez total titulável & $-0,9159^{* *}$ \\
Açúcares totais & $0,8653^{* *}$ \\
Aḉ́cares redutores & $-0,1679$ \\
Açúcares não redutores & $0,8599^{* *}$ \\
\hline ** significativo a $1 \%$ de probabilidade.
\end{tabular}

de maturação I, o índice de degradação de amido indicou menos de $10 \%$ de clareamento no centro da polpa, revelando o estádio de maturação com maior conteúdo de amido $(6,81 \%)$, menor valor de SST $(7,2 \%)$, açúcares não redutores $(0,35)$ e açúcares solúveis totais $(4,11)$. No estádio de maturação $\mathrm{V}$, o índice de degradação indicou mais de $50 \%$ de clareamento, menor conteúdo de amido (3,04\%), maior valor de SST (15,7\%), açúcares não redutores $(10,84)$ e açúcares solúveis totais $(13,59)$. Nos açúcares redutores, houve oscilações durante o amadurecimento dos frutos (Tabela 3); este comportamento também foi observado por Lima (1997), durante o armazenamento de a cultivar Tommy Atkins.

Em geral, para armazenamento em curto prazo, os frutos devem ter, no momento da colheita, $10 \%$ de SST (PROTRADE, 1992; Sañudo et al. 1997), para a exportação devem ter entre $7 \%$ e $8 \%$, (Sañudo et al. 1997) ou 8\% e 9\% (PROTRADE, 1992) por ocasião da colheita. Neste sentido, a colheita para a exportação pode ser feita no estádio de maturação II ou III, visto que não se registrou diferença significativa no teor de SST, nestes dois estádios (Tabela 3). O estádio de maturação III apresentou teor mais elevado de açúcares totais, podendo ser indicado, principalmente, quando o fruto for destinado a mercados mais próximos (Tabela 4).

\section{CONCLUSÃO}

O índice de degradação de amido teve forte correlação com as mudanças no conteúdo de amido, coloração da casca, coloração da polpa, firmeza da polpa, pH, acidez total titulável, sólidos solúveis totais, açúcares redutores e não redutores, podendo, portanto, ser utilizado em nível de campo com eficácia, como mais uma alternativa para estimar a maturação dos frutos. $\mathrm{O}$ produtor poderá utilizar este método e colher os frutos no estádio de maturação mais adequado, dependendo das exigências do mercado consumidor.

Tabela 2 - Mudanças na coloração da casca e coloração da polpa (notas de 1 a 5) e índice de degradação de amido - IDA (notas de 0 a 6), firmeza da polpa (N), acidez total titulável $\left(\mathrm{mmol} \mathrm{H}^{+} / \mathrm{L}\right)$ e $\mathrm{pH}$ em manga ‘Tommy Atkins'. ESAM, Mossoró-RN, 2000.

\begin{tabular}{|c|c|c|c|c|c|c|}
\hline $\begin{array}{l}\text { Estádios de } \\
\text { maturação* }\end{array}$ & $\begin{array}{c}\text { Coloração } \\
\text { da Casca }\end{array}$ & $\begin{array}{c}\text { Coloração } \\
\text { da Polpa }\end{array}$ & Í.D.A & $\begin{array}{c}\text { Firmeza da } \\
\text { Polpa** }\end{array}$ & $\begin{array}{c}\text { Acidez Total } \\
\text { Titulável }\end{array}$ & $\mathrm{pH}$ \\
\hline I & $1,1 \mathrm{e}$ & $1,3 \mathrm{e}$ & $1,5 \mathrm{~d}$ & - & $223,32 \mathrm{a}$ & $3,23 \mathrm{c}$ \\
\hline II & $2,0 \mathrm{~d}$ & $2,1 \mathrm{~d}$ & $1,7 \mathrm{~d}$ & 96,14 a & $197,08 \mathrm{ab}$ & $3,38 \mathrm{~b}$ \\
\hline III & $3,1 \mathrm{c}$ & $2,8 \mathrm{c}$ & $2,7 \mathrm{c}$ & $91,68 \mathrm{a}$ & $174,47 \mathrm{~b}$ & $3,44 \mathrm{~b}$ \\
\hline IV & $4,1 \mathrm{~b}$ & $4,1 \mathrm{~b}$ & $4,4 \mathrm{~b}$ & $78,56 \mathrm{~b}$ & $142,88 \mathrm{c}$ & $3,49 \mathrm{~b}$ \\
\hline V & $5,0 \mathrm{a}$ & $5,0 \mathrm{a}$ & $6,0 \mathrm{a}$ & $9,40 \mathrm{c}$ & $34,22 \mathrm{~d}$ & $4,51 \mathrm{a}$ \\
\hline
\end{tabular}

* Médias seguidas de mesma letra, na vertical, não diferem entre si significativamente, ao nível de 5\% de probabilidade, pelo teste de Tukey.

* * No estádio I, não foi possível determinar a firmeza da polpa dos frutos, pois a leitura ultrapassou a máxima do aparelho ( $30 \mathrm{Ib} /$ plo ${ }^{2}=133,5 \mathrm{~N}$ ); 
Tabela 3 - Mudanças no conteúdo de amido (\% matéria fresca), açúcares totais, açúcares não redutores, açúcares redutores (g/100 $\mathrm{mL}$ ) e sólidos solúveis totais (\%) em manga 'Tommy Atkins'. ESAM, Mossoró-RN, 2000.

\begin{tabular}{cccccc}
\hline $\begin{array}{c}\text { Estádiosde } \\
\text { Maturação* }\end{array}$ & Amido & $\begin{array}{c}\text { Açúcares } \\
\text { Totais }\end{array}$ & $\begin{array}{c}\text { Açúcares Não } \\
\text { Redutores }\end{array}$ & $\begin{array}{c}\text { Açúcares } \\
\text { Redutores }\end{array}$ & $\begin{array}{c}\text { Sólidos Solúveis } \\
\text { Totais }\end{array}$ \\
\hline I & $6,81 \mathrm{a}$ & $4,11 \mathrm{c}$ & $0,35 \mathrm{~d}$ & $3,76 \mathrm{a}$ & $7,2 \mathrm{c}$ \\
II & $5,26 \mathrm{~b}$ & $4,12 \mathrm{c}$ & $1,84 \mathrm{c}$ & $2,45 \mathrm{c}$ & $7,4 \mathrm{c}$ \\
III & $4,62 \mathrm{~b}$ & $5,39 \mathrm{bc}$ & $2,50 \mathrm{bc}$ & $2,89 \mathrm{bc}$ & $7,7 \mathrm{c}$ \\
IV & $4,40 \mathrm{bc}$ & $6,09 \mathrm{~b}$ & $3,00 \mathrm{~b}$ & $3,09 \mathrm{~b}$ & $9,2 \mathrm{~b}$ \\
V & $3,04 \mathrm{c}$ & $13,59 \mathrm{a}$ & $10,84 \mathrm{a}$ & $2,75 \mathrm{bc}$ & $15,7 \mathrm{a}$ \\
\hline
\end{tabular}

* Médias seguidas de mesma letra, na vertical, não diferem entre si significativamente, ao nível de $5 \%$ de probabilidade, pelo teste de Tukey.

TABELA 4 - Resumo das análises de variância para a coloração da casca (C.C), coloração da polpa (C.P), índice de degradação de amido (IDA), amido, firmeza da polpa (F.P), sólidos solúveis totais (SST), acidez total titulável (ATT), pH, açúcares não redutores (ANR), açúcares redutores (AR) e açúcares solúveis totais (AST), em manga 'Tommy Atkins', colhida em diferentes estádios de maturidade. ESAM, Mossoró - RN, 2000.

\begin{tabular}{|c|c|c|c|c|c|c|c|c|c|c|c|c|}
\hline \multirow[b]{2}{*}{ Causa de Variação } & \multicolumn{12}{|c|}{ Valores de F } \\
\hline & GL & C.C & C.P & ID A & Amido & F.P & SST & ATT & $\mathrm{pH}$ & ANR & AR & AST \\
\hline Tratamento & 4 & $1051,42 * *$ & $208,46 * *$ & $85,17 * *$ & $15,96 * *$ & $260,03 * *$ & $189,68 * *$ & $123,74 * *$ & $288,82 * *$ & $223,29 * *$ & $11,03 * *$ & $150,14 * *$ \\
\hline Resíduo & 25 & & & & & & & & & & & \\
\hline CV (\%) & - & 3,87 & 8,20 & 15,51 & 17,42 & 8,90 & 6,75 & 10,47 & 2,05 & 18,18 & 12,09 & 11,90 \\
\hline
\end{tabular}

** significativo ao nível de $1 \%$ de probabilidade.

\section{REFERÊNCIAS BIBLIOGRÁFICAS}

A. O. A. C. Official methods of analysis of the Association of Official Analytical Chemistry. 11 ed. Washington: AOAC, 1992. $1115 \mathrm{p}$.

BLEINROTH, E. W. Determinação do ponto de colheita . In: NETTO, A. G. Manga para exportação: procedimentos de colheita e pós-colheita. Brasília: MAARA/FRUPEX, 1994. 44 p. (Publicações Técnicas, 4).

BROOKFIELD, P. ; MURPAY, P.; HARKER, R. ; MACRAE, E. Starch degradation and starch pattern indices; interpretation and relationship to maturity. Postharvest Biology and Technology, Amsterdan, v.11, p. 23 - 30, 1997.

FAN, X. ; MATTHEIS, J. P.; PATTERSON, M. E.; FELLMAN, J. K. Changes in amylose and total starch content in 'Fuji' apples during maturation. HortScience, Alexandria, v. 30, n. 1, p. 104 $-105,1995$.

KETSA, S. ; CHIDTRAGOOL, S. ; KLEIN, J. D. LURIE, S. Firmness, pectin components and cell wall hydrolases of mango fruit following low-temperature stress. Journal of Horticultural Science \& Biotechnology. Ashford, v. 74, n. 6, p. 685 - 689, 1999.

LAZAN, H.; ALI, Z. M.; SOH, J.; TALKAH, Z. The biochemical basis of differential ripening in mango. Acta Horticulturae,
Leuven, n. 341, p. 501-509, 1993.

LIMA, L. C. de O. Tecido esponjoso em manga 'Tomy Atkins': transformações químicas e bioquímicas no mesocarpo durante o armazenamento. 1997. 184 f. Tese (Doutorado) Universidade Federal de Lavras, Lavras - MG, 1997.

MAIA, G. A. ; SILVA, M. de F. A. e; HOLANDA, L. F. F. de; MONTEIRO, J. C. S. ; ORIÁ, H. F. ; FIGUEIREDO, R. W. de. Estudo da maturação de algumas variedades de manga ( Mangifera indica L.). Revista Brasileira de Fruticultura, Cruz das Almas, v. 8, n. 2, p. $67-74,1986$.

MIZRACH, A. FLITSANOV, U. ; FUCHS, Y. An ultrasonic nondestructive method for measuring maturity of mango fruit. American Society of Agricultural Engineers, Israel, v. 40, n. 4, p. $1107-1111,1997$.

NORUSIS, M. J. SPSSPC statistics. Ilinois: SPSS, 1990.

PROTRADE. Mango - Manual de exportacion: frutas tropicales y hortalizas. Eschborn: GTZ, 1992. 34 p.

SAÑUDO, R. ; BUSTILlOS, R. J. A. ; GARCIA, L. P. de L. ; MOLINA, E. B.; NUÑO, S. O. ; ANGEL, D. N. Manejo postcosecha del mango. EMEX: A. C. 1997.92 p.

SILVA, D. I. Análise de alimentos: métodos químicos e biológicos. Viçosa: 1981.p. 99 - 102.

SOUTHGATE, D.A.T. Determination of foods carbohydrates, London: Elservier Applied Science, 1991. 232p. 